Research Paper:

\title{
Histomorphometrical and Stereological Study of the Lungs in Neona- tal Rats Born to Paraquat-poisoned Pregnant Rats: Protective Effect of Coenzyme Q10
}

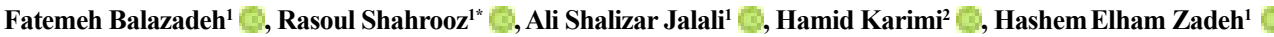

1. Department of Basic Sciences, Faculty of Veterinary Medicine, Urmia University, Urmia, Iran.

2. Department of Basic Sciences, Faculty of Veterinary Medicine, Tabriz University, Tabriz, Iran.

\begin{tabular}{|l|l}
\hline $\begin{array}{l}\text { Use yourdevice to scan } \\
\text { and read the article online }\end{array}$ & $\begin{array}{l}\text { How to cite this paper Balazadeh F, Shahrooz R, Shalizar Jalali A, Karimi H, Elham Zadeh H. Histomorphometrical and Stereo- } \\
\text { logical Study of the Lungs in Neonatal Rats Born to Paraquat-poisoned Pregnant Rats: Protective Effect of Coenzyme Q10. Iranian } \\
\text { Journal of Toxicology. 2020; 14(2):71-80. http://dx.doi.org/10.32598/ijt.14.2.581 }\end{array}$ \\
d &
\end{tabular}

\section{(). 08}

Article info:

Received: 05 Aug 2019

Accepted: 24 Sep 2019

Online Published: 01 Apr 2020

* Corresponding author:

Rasoul Shahrooz, PhD.

Address: Department of Basic Sciences, Faculty of Veterinary Medicine, Urmia University, Urmia, Iran

E-mail: rasoulshahrooz@yahoo.com

\section{ABSTRACT}

Background: Paraquat (PQ), an herbicide, is a very poisonous compound for both humans and animals. This study was conducted to examine the protective effect of the Coenzyme Q10 (CoQ10) in newborn rats from pregnant rats pre-treated with PQ.

Methods: The experiments were conducted on 25 rats, divided in five groups randomly and equally: 1 . Control Group received normal saline $(0.1 \mathrm{ml} /$ day $) ; 2$. PQ Group received PQ only ( $5 \mathrm{mg} / \mathrm{kg} /$ day $) ; 3$. PQ+CoQ10 Group received PQ $(5 \mathrm{mg} / \mathrm{kg})$ and CoQ10 $(10 \mathrm{mg} / \mathrm{kg})$ daily; 4. $\mathrm{PQ}+$ olive oil Group received PQ $(5 \mathrm{mg} / \mathrm{kg})$ and olive oil $(10 \mathrm{mg} / \mathrm{kg})$ daily; 5. Olive oil Group received olive oil $(10 \mathrm{mg} / \mathrm{kg} / \mathrm{day})$. All of the injections were made intraperitoneally and started on the $16^{\text {th }}$ day of pregnancy through to parturition. Sixteen days after parturition, the lungs were removed from the newborn rats, paraffin sections were made and stained with hematoxylin and eosin, and analyzed histomorphometrically and stereologically.

Results: The results revealed that interstitial tissue and lung alveoli had normal structures in the control and olive oil groups. In PQ and PQ-olive oil groups alveolar hemorrhage, inflammation, extensive fibrosis, decreased alveolar numbers, increased mast cells, and changes in the epithelia were observed. In PQ-CoQ10 Group there was a significant recovery in all of the histological alterations.

Conclusion: Generally, Coenzyme Q10 had a protective effect against lung damages caused by $\mathrm{PQ}$, but a complete recovery of the damaged lung tissue would probably take longer than 16 days after birth.

Keywords: Lung tissue damage; Paraquat; Coenzyme Q10; Pregnant rats; Histomorphometry and stereology

\section{Introduction}

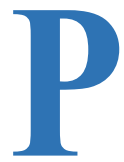

raquat (PQ; 1, 1'-dimethyl-4, 4'-bipyridinium chloride) is widely used as an herbicide; however, it is highly poisonous to both humans and animals [1]. It is also known as a dangerous pollutant to the environment because it can easily bind the soil and organic materials, which takes a long time to be decomposed [2]. Paraquat can rapidly enter the blood and reach all organs and tissues [3]. Lungs are the main target organs in PQ poisoning [4]. Even though the kidneys, heart and nervous system can also be affected, the main reason for death due to $\mathrm{PQ}$ poisoning is the resultant damage and fibrosis of the lung tissue within a few weeks [5]. 
In previous studies on PQ poisoning in mice and the embryos, rats, dogs and rabbits, it was observed that PQ specially affected the lungs in the animals [6]. The PQ toxicity is diagnosed through the progressive interstitial fibrosis and edema of the lungs [7]. Some studies have revealed that when the parents were exposed to herbicides, such as PQ, their offspring might suffer Parkinson's disease and leukemia [5, 7]. These studies suggest that PQ can damage the cell membranes through the induction of multisystem toxicity $[4,8]$.

The mechanism of cellular damage induced by PQ is believed to be cytochrome P450 reductase dependent, causing Reactive Oxygen Species (ROS) formation and membrane lipid peroxidation in the pulmonary cells. Antioxidants prevent oxidative damage caused by ROS in biological structures, and the interactions between antioxidants and toxins can reduce their toxicity [9]. Coenzyme Q10 (CoQ10), also known as ubiquinone, is a vitamin-like substance in all cells residing in the endoplasmic reticulum, peroxisome, lysosome and mitochondrial membranes. In recent years, considerable attention has been paid to CoQ10 as a nutritional supplement that inhibits some of the damages caused by ROS [10].

Previous studies have shown the protective effects of CoQ10 in different models of tissue damage induced by oxidative stress and inflammatory reactions [11-13]. This coenzyme is used in many disorders for its protective and antioxidant properties [12]. In the clinical application, CoQ10 is used as a therapeutic agent for chronic diseases, such as heart failure, muscular dystrophy, Parkinson's disease, cancer and diabetes [13]. The purpose of this study was to investigate the protective effect of CoQ10 against the PQ-induced oxidative damage during the gestational period and histogenesis of the lungs in rat neonates, which has not been studied before.

\section{Materials and Methods}

Materials: In this experimental study, 25 adult Wistar rats (15 female, 10 male), weighing 200-250 g, were obtained from the Animal Resource Center, School of Veterinary Medicine, Urmia University, Urmia, Iran. Animals were kept under standard conditions of $12 \mathrm{~h}$. light and $12 \mathrm{~h}$, dark at $25^{\circ} \mathrm{C}\left( \pm 2^{\circ} \mathrm{C}\right)$ of the ambient temperature and relative humidity of $50 \%( \pm 10 \%)$. All of the animals had free access to water and pellet food. The rats' behaviors were accurately recorded throughout the study. Fallowing a week of adaptation to the laboratory environment and checking the weights, the animals were randomly divided into five groups of five rats each, with two male rats per group.
The presence of a vaginal plug and sperms in the rats' vagina was designated as the first day of pregnancy. The treatments started on the $16^{\text {th }}$ day of gestation until parturition (day 21). Supplies of CoQ10 and PQ were purchased from Sigma-Aldrich (Saint Louis, MO, USA) and Exir Company (Tehran, Iran), respectively. Paraquat was dissolved in normal saline prior to injection into the animals.

Treatments: All injections were made intraperitoneally and once daily as follows:

Control Group received normal saline $(0.1 \mathrm{ml} /$ day).

$P Q$ Group received only $P Q(5 \mathrm{mg} / \mathrm{kg} /$ day $)$.

$P Q+$ CoQ10 Group received $P Q(5 \mathrm{mg} / \mathrm{kg})$ and $C o Q 10$ $(10 \mathrm{mg} / \mathrm{kg})$ daily.

$P Q+$ olive oil Group received $P Q(5 \mathrm{mg} / \mathrm{kg})$ and olive oil (10 mg/kg) daily.

Olive oil Group received olive oil only (10 mg/kg/day).

All injections were made intraperitoneally and started on the $16^{\text {th }}$ day of pregnancy until parturition (a total of 6 days). Then, the lungs were removed from the newborn rats 16 days after parturition, paraffin sections were prepared, stained with hematoxylin and eosin, and analyzed histomorphometrically and stereologically.

At the end of the experiment, all newborn rats were weighed on the $16^{\text {th }}$ day after birth and then euthanized. All the ethical requirements were observed based on the guidelines of the Ethics Committee of the School of Veterinary Medicine, Urmia University, Urmia, Iran (Registration Code: IR-UU-AEC-487/PD3). The right lungs were sampled and fixed in $10 \%$ buffered formalin solution. After the lung tissue processing, paraffin sections were made $(5 \mu \mathrm{m}$ thick) by rotary microtome (Microtome, $\mathrm{GmbH}$, Germany). After staining with hematoxylin and eosin, histomorphometrical and stereological studies were conducted in terms of the volume, numerical densities and mean number of alveoli, bronchioles, fibroblasts and mast cells in the lung tissue samples. In order to estimate the volume density, the tissue sections were studied at equal distances (by removing 20 paraffin sections or $100 \mu$ between two sections in sequence). In addition, to examine the elastic and collagen fibers, Verhoeff's and Masson's trichrome staining methods were used, respectively. Also, toluidine blue method was used to visualize the mast cells. In the stereological study of 
volume and numerical densities, the following formulas were used:

$$
\text { Volume density }(\mathrm{mm} 3)=d \times \sum p \times a(p)[14]
$$

Where " $d$ " is the distance between cuts $(100 \mu)$; " $\sum \mathrm{p}$ " is the total number of focal points considered in each section, and "a (p)" is the focal point considered in each grade point.

\section{Numerical density $=N A /(D+T)[15]$}

Where "NA" is the number of profiles per unit area; " $\mathrm{D}$ " is the mean diameter and " $T$ " is the average thickness of the sections.

Statistical Analyses: The data were treated statistically, using SPSS software v. 18 via one way ANOVA and Tukey's analyses. The $\mathrm{P} \leq 0.05$ was considered statistically significant among the data differences.

\section{Results}

\section{Histological Studies}

Group 1: Histological studies of the lung tissues in the control group revealed that on the $16^{\text {th }}$ day after birth, the alveoli had grown and sufficiently extended with the inter-alveolar septa being thoroughly thin. It was also noted that type one alveolar cells with flat nuclei lined the inner surface of alveoli. The type two alveolar cells had spherical nuclei and were seen in the inner surface of the alveoli in some sections. The interstitial tissue was only slightly thick in some areas.

Group 2: The results demonstrated that most of the pulmonary alveoli were small but some of them were distended in Group 2 (PQ only). In addition, the interalveolar septa were thicker and the interstitial tissue had a higher cellular population than those in Group 1 (controls), as seen in most sections. Most inter-alveolar septa in this group were short and incomplete, with hyperemia noted in the interstitial tissue.

Group 3: The histological study of the lung tissues in Group $3(\mathrm{CoQ} 10 \rightarrow$ PQ) revealed that the number of alveoli with large diameters increased compared with those noted in Group 2 (PQ only). However, some alveoli with small diameters were also observed in this group. In some histological sections, there was an accumulation of interstitial tissue. Also, it was revealed that the inter-alveolar septa were thinner compared with those seen in Group 2. It was also noted that the hyperemia in the interstitial tissue was significantly less than that of the Group 2.

Group 4: The only significant histological finding noted in Group 4 (PQ+olive oil) was the number of alveoli, which was higher than those seen in Group 2 (PQ only).

Group 5: The histological findings in Group 5 (olive oil only) revealed that the lung tissue was essentially sim-

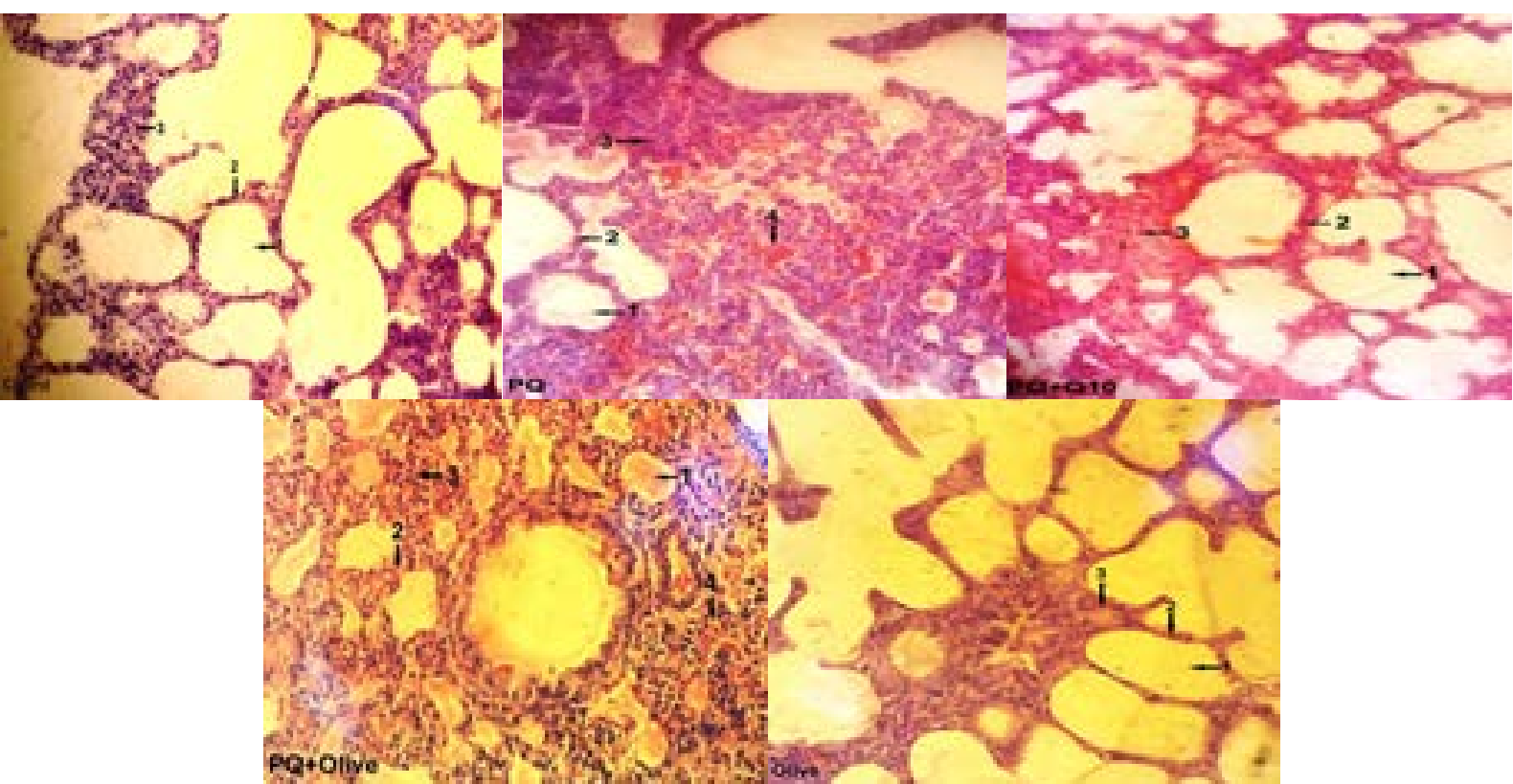

Figure 1. Histological sections of the rats lung tissue

1: Alveoli; 2: Inter alveolar septum; 3: Interstitial tissue; 4: Hyperemia. (H \& E staining; mag. 400×) 


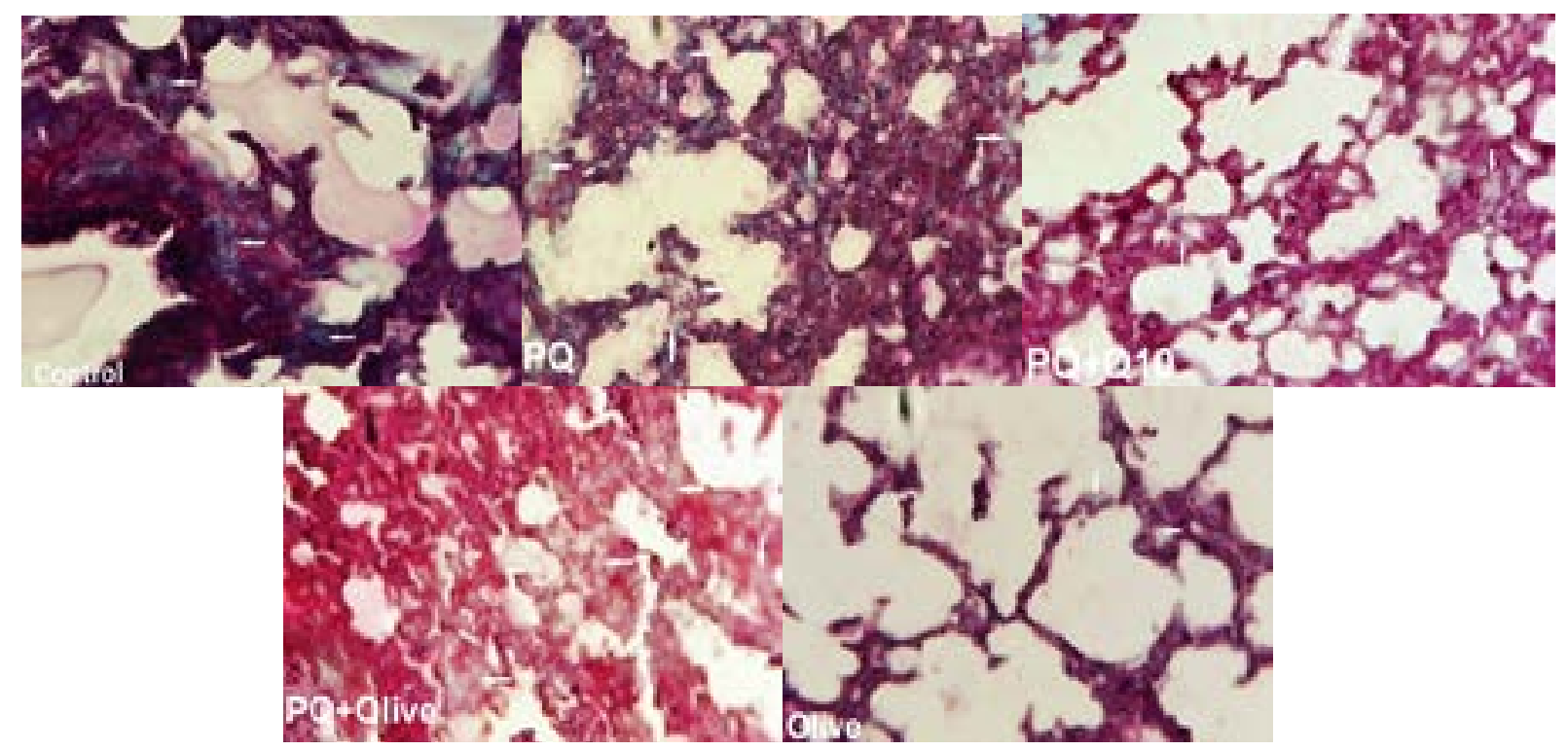

Figure 2. Histological sections of the rats' lung tissue, showing collagen foci (arrows) and fibrous tissue induced by Paraquat toxicity

Mason's trichrome staining; mag. 400×.

ilar to those seen in the control group, without any negative effects associated with olive oil (Figures 1 and 2).

\section{Histomorphometrical and Stereological studies}

Number of Bronchioles: The study of bronchioles in the rats' lung tissue revealed that the mean number of bronchioles was not significantly different between Groups 1 and 2. This number increased significantly in Group 5 (olive oil only) compared to those in Group 2. However, the number of bronchioles was not significantly different among other groups (Groups 1-4) (Figure 3). Also, the mean diameter of bronchioles among different groups was not significantly different (Figure 4).

Number of alveoli: The evaluation of the mean number of alveoli in the lung tissue for different groups revealed that the number of alveoli per unit area $\left(1 \mathrm{~mm}^{2}\right)$ was decreased significantly in Group 2, while the administration of CoQ10 followed by PQ significantly reversed this effect. Further, the use of olive oil with PQ did not cause a significant increase in the number of alveoli. The mean number of alveoli in the olive oil group was similar to that of the control group (Figure 5).

Alveolar diameter: The analysis of the mean alveolar diameter among the groups indicated that this feature in the groups receiving PQ [2-4] decreased significantly $(\mathrm{P}<0.05)$ compared to those in Groups 1 and 5 (controls $\&$ olive oil). Further, there was no significant difference among the groups receiving PQ with respect to the alveolar diameters (Figure 6).

Alveolar Volume: The volume density evaluation of the lung alveoli showed a significant decrease in the PQ group compared to those in the control group $(\mathrm{P}<0.05)$.

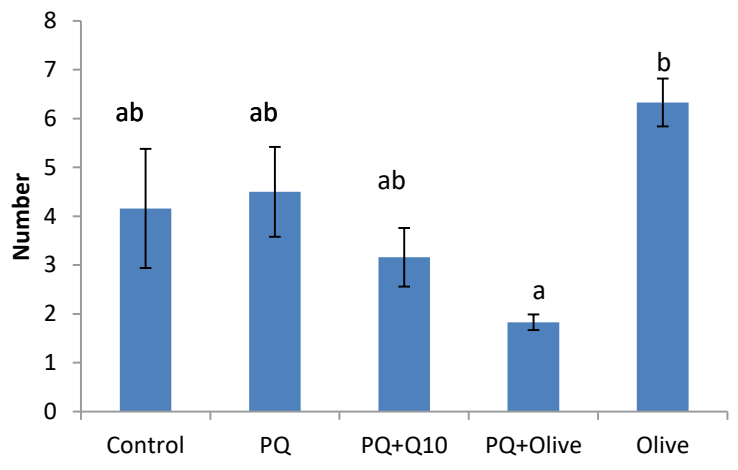

Figure 3. Average number of the rats' lung tissue bronchioles

Superscripts $(a, b)$ show the significant differences between the groups $(\mathrm{P}<0.05)$. 


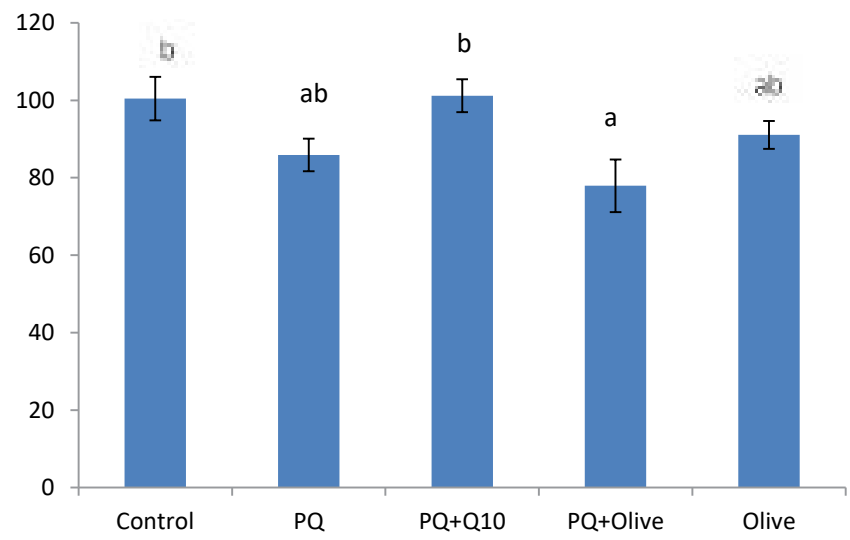

Figure 4. Average diameter of bronchioles in the rats' lung tissue

Superscripts $(a, b)$ show the significant differences between the groups $(\mathrm{P}<0.05)$.

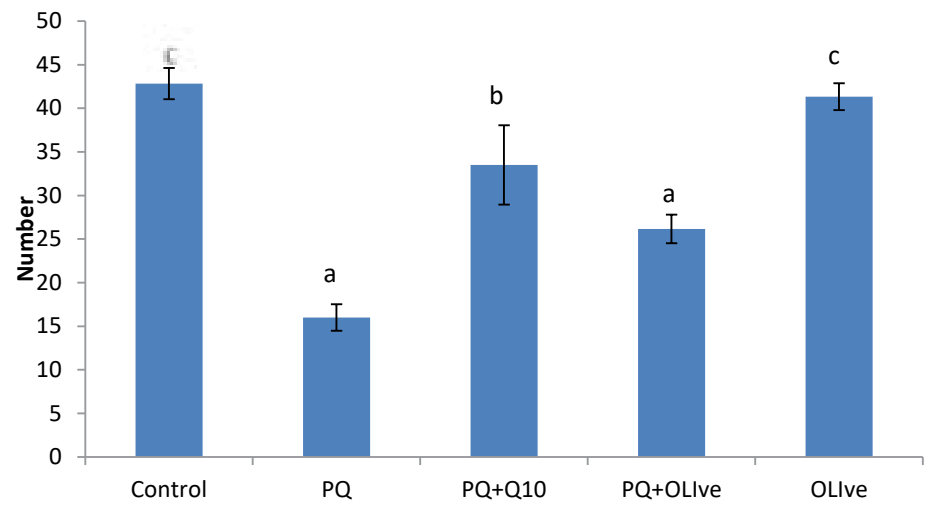

Figure 5. Average number of alveoli in the rats' lung tissue

Superscripts $(a, b, c)$ show the significant differences between the groups $(P<0.05)$.

The alveolar volume did not change significantly within Groups 2, 3 and 4 that received PQ. With respect to alveolar volume density, rats in Group 5 were as healthy as those in the control group (Figure 7).
Fibroblasts: The evaluation of the fibroblasts in the lung tissue showed that the mean number of these cells in Groups 2 and 4 (PQ \& PQ+olive oil) was significantly higher than that in other groups $(\mathrm{P}<0.05)$. However, in Group 3 (CoQ10 $\rightarrow$ PQ) the mean number of fibroblasts decreased signifi-

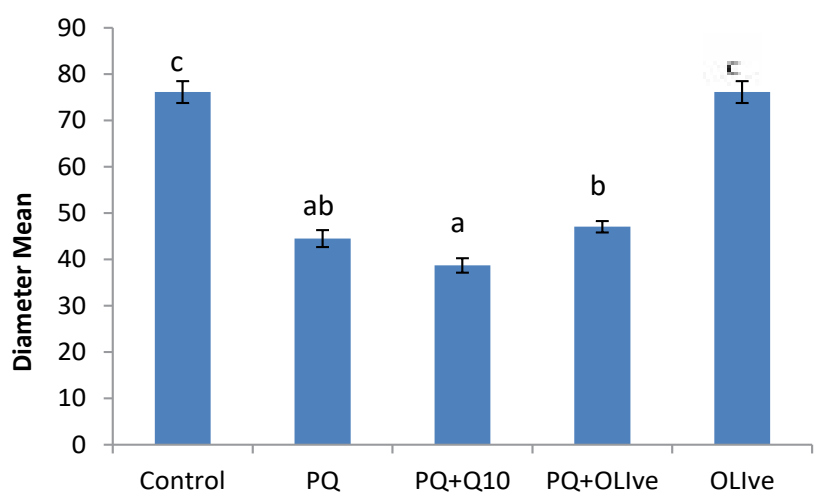

Figure 6. Average diameter of the alveoli in the rats' lung tissue

Superscripts $(a, b)$ show the significant differences between the groups $(\mathrm{P}<0.05)$. 


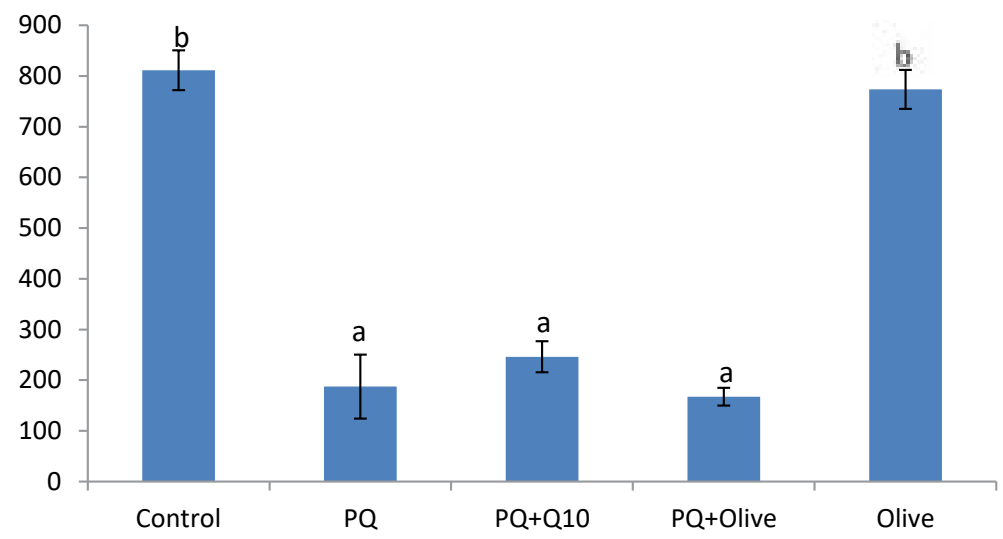

Figure 7. Volume density of alveoli in the rats' lung tissue

Superscripts $(a, b)$ show the significant differences between the groups $(\mathrm{P}<0.05)$.

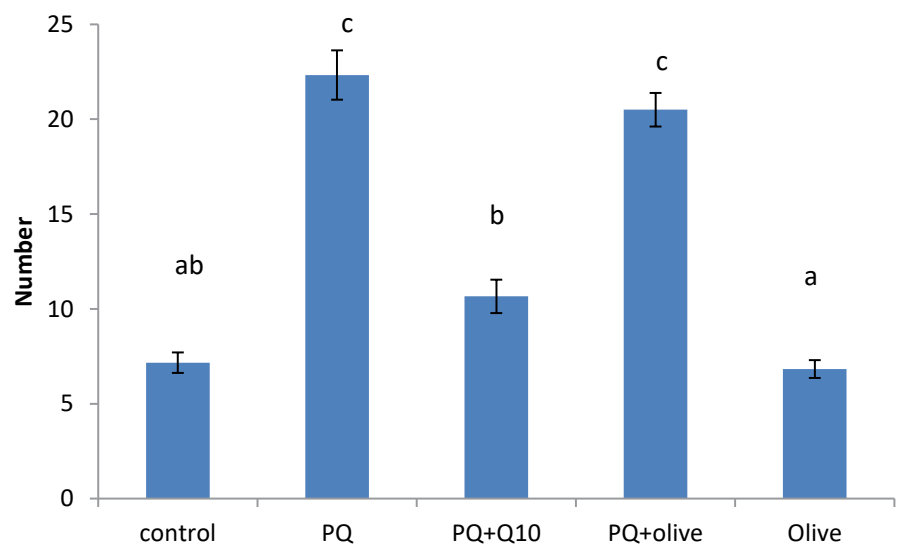

Figure 8. Average number of fibroblasts in the rats' lung tissue

Superscripts $(a, b, c)$ show the significant differences between the groups $(P<0.05)$.

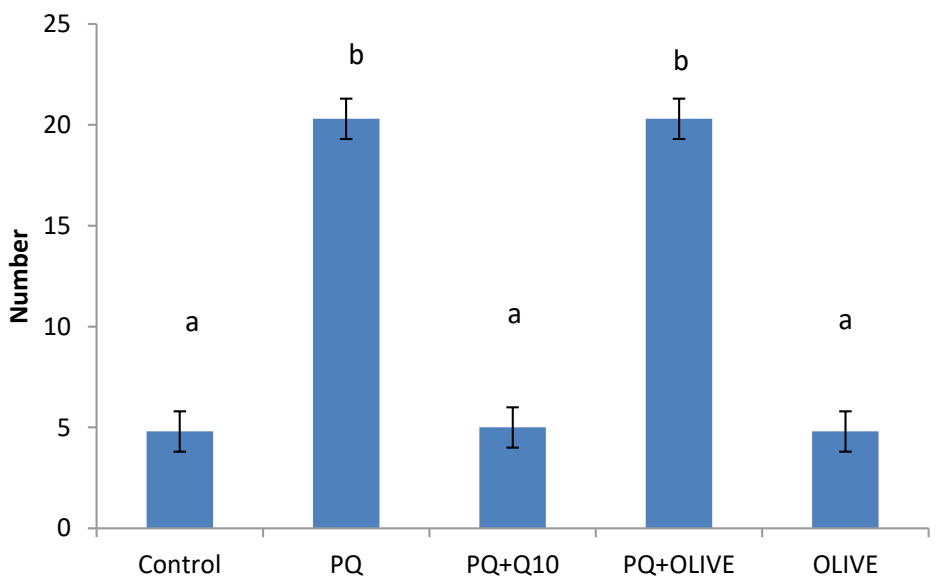

Figure 9. Average number of mast cells in the rats' lung tissue

Superscripts $(a, b)$ show the significant differences between the groups $(P<0.05)$. 


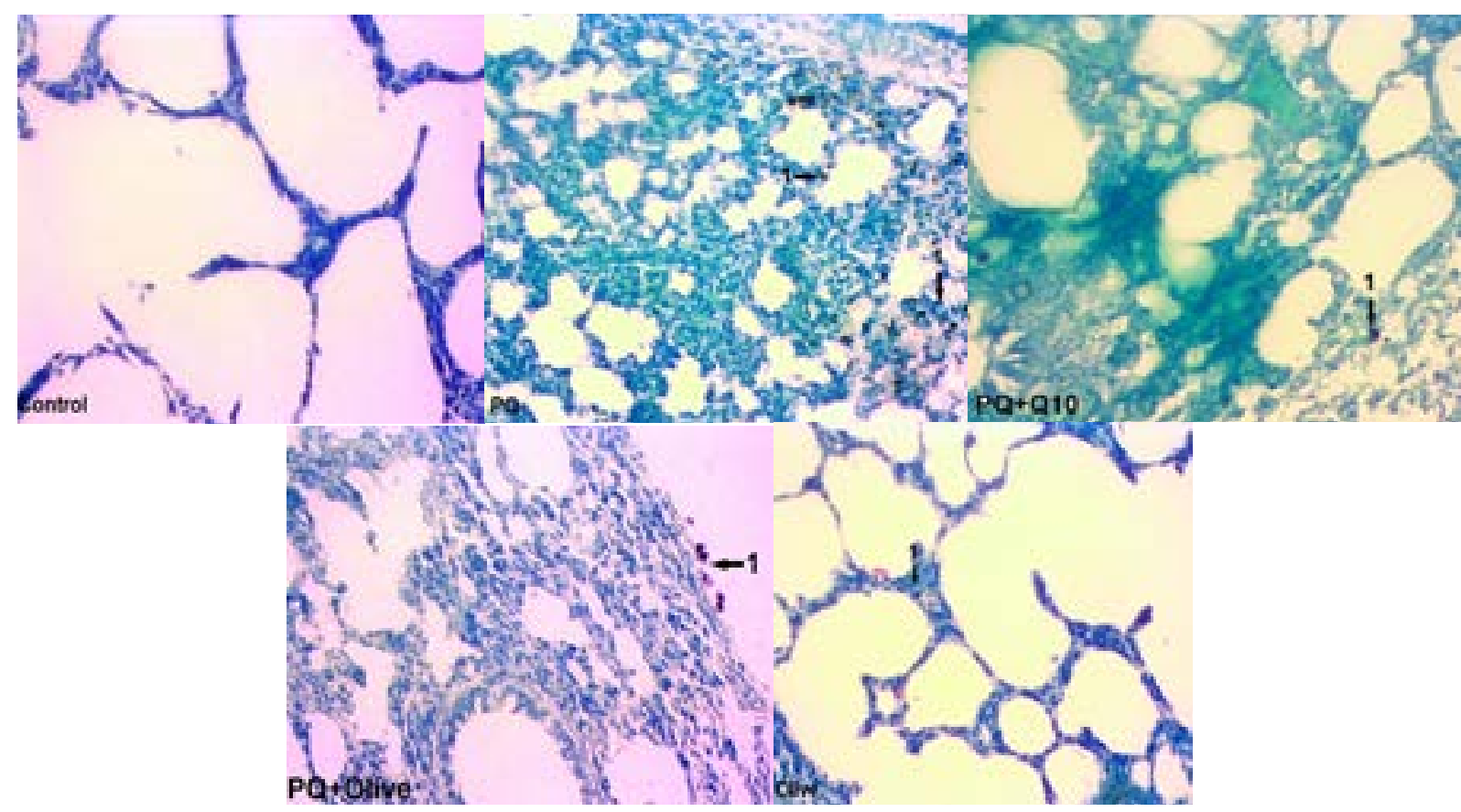

Figure 10. Histological sections of rats' lung tissue showing mast cells (arrows) in the interstitial tissue

Toluidine blue staining; mag. 400×.

cantly compared to that in Group 5 (olive oil), but insignificantly compared to the controls $(\mathrm{P}<0.05)$ (Figure 8$)$.

Mast Cells: The evaluation of the mast cells present in the lung tissue showed that the mean number of mast cells was significantly higher in Groups 2 and 4 (PQ \& $\mathrm{PQ}+$ olive oil) than those in Groups 1,3 and $5(\mathrm{P}<0.05)$. Although Groups 1, 3 and 5 contained the least number of mast cells, there were no significant differences among them (Figures 2, $9 \& 10$ ).

\section{Discussion}

Paraquat is used as an herbicide and has a fast-paced activity, causing electron transfer in plants and prevents the production of NADPH. This process leads to the production of hydrogen peroxide, which serves as an oxidizing agent against cellular molecules, especially the unsaturated lipids in the cell membranes. It has been shown that PQ causes local intracellular edema in one percent of the epithelial cells of the mice terminal bronchioles within an hour after administration and results in extensive degradation after $24 \mathrm{~h} \mathrm{[16].} \mathrm{However,} \mathrm{the}$ damaging effect on the bronchioles declines $24 \mathrm{~h}$ after PQ administration [17]. Furthermore, it has been reported that PQ can be detected in the bronchiolar epithelia 3 $\mathrm{h}$ after its intravascular injection [18].
Also, the absorption of PQ by bronchial epithelial layer has been observed within $24 \mathrm{~h}$ after the intravascular injection of PQ [19]. The present study showed that the mean number and diameter of bronchioles did not change significantly among different groups on day 16 after the birth of baby rats. While, most changes occurred at the terminal airways and the alveoli, it is likely that the amount of PQ passed from placenta to the baby rats was not enough to significantly affect the number and diameter of the bronchioles. Alternatively, PQ should have been administered earlier than the $16^{\text {th }}$ day of gestation to observe a significant effect.

Based on the results, the mean alveolar number was significantly lower in Group $2(\mathrm{PQ})$ than that in the control and olive oil groups (Groups $1 \& 5$ ). The administration of PQ $2 \mathrm{~h}$ after CoQ10 (Group 3) minimized or prevented the oxidative effect of $\mathrm{PQ}$, causing the development of significantly higher number of alveoli compared with that in Group $2(\mathrm{PQ})$. Our results also showed that the administration of olive oil together with PQ did not neutralize the oxidative effect of PQ. We further found a compensatory improvement in the alveolar diameter subsequent to the use of CoQ10. This might have required the presence of CoQ10 earlier than the $16^{\text {th }}$ day of gestation for sufficient alveolar development.

We found that the mean alveolar diameter in Group 3 was approximately the same as that of Group 2. Also, 
the alveolar volume density showed no significant difference between Groups 2 and 3, despite the compensatory effects of CoQ10 on the number of the alveoli. The paraquat toxicity is related to its ability to initiate lipid peroxidation leading to damaged cellular membranes and ultimately cell death [20]. It has been reported that micro-viscosity of the membrane declines due to membrane peroxidation, leading to local tissue hemorrhage [21]. Our histological findings confirmed the toxic effects of PQ on the baby rats' lung tissue. It is known that paraquat accumulates slowly in the lungs through an energy-dependent process [22]. The elimination of PQ in its intact form occurs in two ways - a large amount through the urine and a scant amount through the bile [23]. In mammalians, the primary damage caused by PQ occurs in the lungs, by accumulating in type I and II alveolar epithelia and Clara cells [24, 25].

Morphological damages caused in the lungs by PQ are initially identified as primary destructive phase, in which types I and II alveolar epithelia are damaged. Subsequently, a proliferative phase occurs that is characterized as alveolitis, pulmonary edema and infiltration of inflammatory cells $[24,25]$. It has been suggested that intra-alveolar hemorrhage, edema, extensive fibrosis and changes in epithelia can occur in the lungs following PQ toxicity [26]. During the acute toxic phase, tissue edema, vacuolization, and mitochondrial or endoplasmic disorder of type I and II pneumocytes can occur [27]. This phase is followed by a progressive pulmonary fibrosis, associated with alveolar degradation [28].

In the present study, the evaluation of mean number of fibroblasts indicated a rise in the pulmonary interstitial connective tissue. In Group 2, the number of fibroblasts in the lung tissue increased significantly and caused tissue fibrosis compared to that in the control group. In contrast, the proliferation of fibroblasts in Group 3 was significantly prevented in the presence of CoQ10. The use of olive oil with PQ (Group 4); however, did not provide a significant protective effect.

The presence of mast cells under oxidative stress represents inflammation. In Group 2 (PQ), the number of mast cells was significantly increased compared to that in the controls, while the anti-inflammatory effects of CoQ10 in Group 3 resulted in a reduction in number of mast cells, similar to that seen in the controls. The use of olive oil plus PQ had no anti-inflammatory effects on the average number of mast cells. In addition, the study of all parameters showed that the use of olive oil alone did not have any toxic effects and these parameters did not differ significantly from the healthy control group. In a previous study on rats, it was shown that mast cells and fibroblasts proliferated approximately three to four weeks after an intraperitoneal injection of PQ [29]. It is known that mast cells increase in the lung interstitial tissues, leading to fibrosis [30]. The fibrosis is likely to be linked to histamine, a major inflammatory mediator released by mast cells which enhances collagen synthesis [31].

The present study demonstrated that the antioxidant effect of CoQ10 had a significant protective effect in rats poisoned with PQ and protected the lungs from damage [32]. CoQ10 is an essential coenzyme and serves in the electron transfer chain as a strong antioxidant and anti-inflammatory agent in mitochondria and other lipid membranes [33]. Likewise, it has been noted that CoQ10 can be effective in reducing the free radicals and inhibits lipid peroxidation in patients poisoned with paraquat $[34,35]$.

\section{Conclusions}

Based on our results, it can be concluded that PQ is able to pass from the placenta to the embryo through the blood in pregnant rats, affecting the lungs histogenesis in the newborns. The major pathological changes in the lung tissue were in the diameter and number of alveoli, as well as destructive changes in the interstitial tissue. The observed increase in the number of alveoli and the decrease in the interstitial tissue, and mast cells are likely to be related to the antioxidant properties of CoQ10. Finally, we can conclude that the administration of CoQ10 is recommended to prevent PQ toxicity complications. Future studies should allow longer period of time than 16 days post partum to explore whether further improvement in the lung tissue damages may occur.

\section{Ethical Considerations}

\section{Compliance with ethical guidelines}

All ethical principles were considered in this article. The participants were informed about the purpose of the research and its implementation stages; they were also assured about the confidentiality of their information. Moreover, they were allowed to leave the study whenever they wish, and if desired, the results of the research would be available to them.

\section{Funding}

The present paper extracted from the $\mathrm{PhD}$. dissertation of the first author Department of Basic Sciences, Faculty of Veterinary Medicine, Urmia University. 


\section{Author's contributions}

Conceptualization: Rasoul Shahrooz; Methodology: Fatemeh Balazadeh, Rasoul Shahrooz, and Ali Shalizar Jalali; Investigation: Fatemeh Balazadeh; Writing-original draft: Fatemeh Balazadeh and Hamid Karimi; Writing-review \& editing: Rasoul Shahrooz and Elham Zadeh Hashem; Resources: All authors; Supervision: Rasoul Shahrooz and Ali Shalizar Jalali.

\section{Conflict of interest}

The authors declared no conflict of interests.

\section{References}

[1] Tortorelli MC, Hernández DA, Vázquez GR, Salibián A. Effects of paraquat on mortality and cardiorespiratory function of catfish fryPlecostomus commersoni. Arch Environ Contam Toxicol. 1990; 19(4):523-9. [DOI:10.1007/BF01059071] [PMID]

[2] Watts M. Pesticide Action Network Asia and the Pacific (PANAP). Penang, Malaysia, 2011 [Internet]. 2015 [Updated 2015 Feb 15]. Available from: http://wssroc.agron.ntu.edu. tw/note/Paraquat.pdf

[3] Becking GC, Chen BH. International Programme on Chemical Safety (IPCS): Environmental health criteria on boron human health risk assessment. Biol Trace Elem Res. 1998; 66(13):439-52. [DOI:10.1007/BF02783154] [PMID]

[4] Murray RE, Gibson JE. Paraquat disposition in rats, guinea pigs and monkeys. Toxicol Appl Pharmacol. 1974; 27(2):28391. [DOI:10.1016/0041-008X(74)90199-9]

[5] Mohammadi-Karakani A, Ghazi-Khansari M, Sotoudeh M. Lisinopril ameliorates paraquat-induced lung fibrosis. Clin Chim Acta. 2006; 367(1-2):170-4. [DOI:10.1016/j. cca.2005.12.012] [PMID]

[6] Fennelly JJ, Gallagher JT, Carroll R. Paraquat poisoning in a pregnant woman. Br Med J.1968;3(5620):722-3. [DOI:10.1136/ bmj.3.5620.722] [PMID] [PMCID]

[7] Clark D, McElligott T, Hurst EW. The toxicity of paraquat. Occup Environ Med. 1966; 23(2):126-32. [DOI:10.1136/ oem.23.2.126] [PMID] [PMCID]

[8] Toner PG, Vetters JM, Spilg WGS, Harland WA. Fine structure of the lung lesion in a case of paraquat poisoning. J Pathol. 1970; 102(3):182-5. [DOI:10.1002/path.1711020311] [PMID]

[9] Dick FD. Parkinson's disease and pesticide exposures. Br Med Bull. 2006; 79-80(1):219-31. [DOI:10.1093/bmb/ld1018] [PMID]

[10] Monge P, Wesseling C, Guardado J, Lundberg I, Ahlbom A, Cantor K, et al. Parental occupational exposure to pesticides and the risk of childhood leukemia in Costa Rica. Scand J Work Environ Health. 2007; 33(4):293-303. [DOI:10.5271/ sjweh.1146] [PMID]
[11] Bus JS, Aust SD, Gibson JE. Paraquat toxicity: Proposed mechanism of action involving lipid peroxidation. Environ Health Perspect. 1976; 16:139-46. [DOI:10.1289/ehp.7616139] [PMID] [PMCID]

[12] Murray RK, Rodwell VW, Bender D, Botham KM, Anthony Weil P, Kennelly PJ. Harper's illustrated biochemistry. $28^{\text {th }}$ ed. New York City: McGraw Hill Professional; 2009. https:// books.google.com/books?id=XSZKD1EdKBoC\&dq

[13] Linnane AW, Kopsidas G, Zhang C, Yarovaya N, Kovalenko S, Papakostopoulos $\mathrm{P}$, et al. Cellular redox activity of Coenzyme Q10: Effect of CoQ 10 supplementation on human skeletal muscle. Free Radic Res. 2002; 36(4):445-53. [DOI:10.1080/10715760290021306] [PMID]

[14] Upaganlawar A, Farswan M, Rathod Sh, Balaraman R. Modification of biochemical parameters of gentamicin nephrotoxicity by Coenzyme Q10 and green tea in rats. Indian J Exp Biol. 2006; 44(5):416-8. https:/ / www.researchgate.net/ publication/7072630

[15] Alleva R, Tomasetti M, Battino M, Curatola G, Littarru GP, Folkers K. The roles of Coenzyme Q10 and vitamin E on the peroxidation of human low density lipoprotein subfractions. Proc Natl Acad Sci U S A. 1995; 92(20):9388-91. [DOI:10.1073/ pnas.92.20.9388] [PMID] [PMCID]

[16] Keith M, Geranmayegan A, Sole MJ, Kurian R, Robinson A, Omran AS, et al. Increased oxidative stress in patients with congestive heart failure. J Am Coll Cardiol. 1998; 31(6):1352-6. [DOI:10.1016/S0735-1097(98)00101-6]

[17] Gundersen HJG. Notes on the estimation of the numerical density of arbitrary profiles: The edge effect. J Microsc. 1977; 111(2):219-23. [DOI:10.1111/j.1365-2818.1977.tb00062.x]

[18] Loud AV. A quantitative stereological description of the ultrastructure of normal rat liver parenchymal cells. J Cell Biol. 1968; 37(1):27-46. [DOI:10.1083/jcb.37.1.27] [PMID] [PMCID]

[19] Etherton JE, Gresham GA. Early bronchiolar damage following paraquat poisoning in mice. J Pathol. 1979; 128(1):21-7. [DOI:10.1002/path.1711280105] [PMID]

[20] Thurlbeck WM, Thurlbeck SM. Pulmonary effects of paraquat poisoning. Chest.1976;69(2Suppl):276-80. [DOI:10.1378/ chest.69.2_Supplement.276]

[21] Nagao M, Takatori T, Wu B, Terazawa K, Gotouda H, Akabane $\mathrm{H}$, et al. Immunohistochemical localization of paraquat in lung and brain. Med Sci Law. 1991; 31(1):61-4. [DOI:10.117 7/002580249103100111] [PMID]

[22] Webb DB. The autoradiographic localization of paraquat in the lung. Br J Exp Pathol. 1980; 61(2):217-21. [PMID] [PMCID]

[23] Franzen D, Boer F, Heitz W, Mecking H, Eidt S, Käferstein $\mathrm{H}$, et al. Failure of radiotherapy to resolve fatal lung damage due to paraquat poisoning. Chest. 1991; 100(4):1164-5. [DOI:10.1378/chest.100.4.1164] [PMID]

[24] Salmona M, Donnini M, Perin L, Diomede L, Romano M, Marini MG, et al. A novel pharmacological approach for paraquat poisoning in rat and $\mathrm{A} 549$ cell line using ambroxol, a lung surfactant synthesis inducer. Food Chem Toxicol. 1992; 30(9):789-94. [DOI:10.1016/0278-6915(92)90081-U]

[25] Rose MS, Smith LL, Wyatt I. Evidence for energy-dependent accumulation of paraquat into rat lung. Nature. 1974; 252(5481):314-5. [DOI:10.1038/252314b0] [PMID] 
[26] Bus JS, Gibson JE. Paraquat: Model for oxidant-initiated toxicity. Environ Health Perspect. 1984; 55:37-46. [DOI:10.1289/ ehp.845537] [PMID] [PMCID]

[27] Kimbrough R, Gaines T. Toxicity of paraquat to rats and its effect on rat lungs. Toxicol Appl Pharmacol. 1970; 17(3):67990. [DOI:10.1016/0041-008X(70)90042-6]

[28] Gawarammana IB, Buckley NA. Medical management of paraquat ingestion. Br J Clin Pharmacol. 2011; 72(5):745-57. [DOI:10.1111/j.1365-2125.2011.04026.x] [PMID] [PMCID]

[29] Dinis-Oliveira RJ, Sousa C, Remião F, Duarte JA, Sánchez Navarro A, Bastos ML, et al. Full survival of paraquatexposed rats after treatment with sodium salicylate. Free Radic Biol Med. 2007; 42(7):1017-28. [DOI:10.1016/j.freeradbiomed.2006.12.031] [PMID]

[30] Smith P, Heath D, Kay J. The pathogenesis and structure of paraquat-induced pulmonary fibrosis in rats. J Pathol. 1974; 114(2):57-67. [DOI:10.1002/path.1711140202] [PMID]

[31] Selman M, Montaño M, Ramos C, Barrios R, Pérez-Tamayo R. Experimental pulmonary fibrosis induced by paraquat plus oxygen in rats: A morphologic and biochemical sequential study. Exp Mol Pathol. 1989; 50(2):147-66. [DOI:10.1016/00144800(89)90027-0]

[32] Haslam PL, Cromwell O, Dewar A, Turner-Warwick M Evidence of increased histamine levels of lung lavage fluids from patients with cryptogenic fibrosing alveolitis. Clin Exp Immunol. 1981; 44(3):587-93. [PMID] [PMCID]

[33] Goto T, Befus D, Low R, Bienenstock J. Mast cell heterogeneity and hyperplasia in bleomycin-induced pulmonary fibrosis of rats. Am Rev Respir Dis. 1984; 130(5):797-802. [PMID]

[34] Abdel-Hady EK, Abdel-Rahman GH. Protective Role of Coenzyme Q10 against Paraquat Induced Hepatotoxicity in Male Rats. Life Sci J. 2013; 10(1):1933-40. https://www. semanticscholar.org/paper/Protective-Role-of-CoenzymeQ-10-against-Paraquat-1-Abdelhady-Abdelrahman/af0264bf062771c9f1c04440907e2ad3fb695c08

[35] Littarru GP, Tiano L. Clinical aspects of Coenzyme Q10: An update. Nutrition. 2010; 26(3):250-4. [DOI:10.1016/j. nut.2009.08.008] [PMID] 